\title{
Consumers' Perceptions of Price Steering in Shopping Online for Tourism
}

\author{
Dr Jean Michel CHAPUIS \\ Academic Dean - Higher Education \\ FERRANDI Paris, CCI Paris Ile-de-France, 28, rue de l'abbé Grégoire \\ 75006 Paris - France. EIREST, Université Paris 1 Panthéon-Sorbonne \\ E-mail: jmchapuis@ferrandi-paris.fr
}

Received: May 5, 2021 Accepted: July 13, $2021 \quad$ Published: July 13, 2021

doi:10.5296/jmr.v13i3.18810 URL: https://doi.org/10.5296/jmr.v13i3.18810

\begin{abstract}
When confronting discriminations during the buying process, the consumers may perceive unfair transactions and some untrustworthy providers. Price steering is a common manipulation of listing offers tailored to a customer's request. The consumers receive a same-products list in a different order for the same query on e-shop. The study questions whether its performance is related to discrimination among consumers. This paper mobilizes the theory of Justice to explore perceptions of fairness and trust in the practice of price steering. The proposed framework states that the post-purchase stage reveals perceptions intervening in the effect of price steering on willingness to pay.

An experiment with a total 883 respondents is simulating an online shopping. The list of options shown online is manipulated. This study documents the main effect of price steering such as a higher willingness to pay and driving online purchasers toward certain choices. This effect is found to generate up to $20 \%$ of extra revenue. The analysis also finds a negative influence on perceptions with no difference between the discriminated segments of the market. Implications for researchers and managers: the pricing schemes should be carefully tailored to maintain fairness, as well as profitability, by considering rate parity across online channels and purchasing experiences.
\end{abstract}

Keywords: online shopping, willingness to pay, perceived fairness, tourism management research 


\section{Introduction}

2021, Vol. 13, No. 3

Personalization in web search helps a provider to give the user more relevant products. Price steering occurs when users receive different product results (or the same products in a different order) for the same query on an e-shop (Hannak et al., 2014). The Wall Street Journal revealed that Mac users were steered to pricier hotels on Orbitz Worldwide Inc (Mattioli, 2012). Chiames (2014) argued that the Orbtiz's algorithms determining the list of products shown on a buyer's screen aim at providing information relevant to him/her. It was identified that Mac users are $40 \%$ more likely to book a four- or five-star hotel than PC users for instance. E-tourism is, unless the COVID lockdowns, a major component of e-commerce where manipulations often occur.

The efficiency of online personalization, like price steering, relies on the framing effect. Tversky and Kahneman (2013) addressed the framing of decision-making of individual emphasizing the role of information. Communications can be framed in terms of the gains or losses associated with a particular behavior. The framing of such persuasive messages influences decision making (Rothman \& Salovey, 1997). Message framing is contented in several factors: the regulatory focus (i.e., prevention-focus vs. promotion focus); the construal level and the relevance (Heo \& Lee, 2010; Kimes \& Wirtz, 2003). The influence of framed information on decision making is contingent on people. The purpose of this study is to understand how discriminations during the buying process intervene with consumer's choice during the shopping online for tourism.

Modeling choices - such as willingness to pay (hereafter WTP) - at the individual level is consistent for managers. The methodology is theoretically sound (McFadden, 1984). Reynisdottir et al., 2008, for instance, estimated the willingness to pay in tourism. Sharifi-Tehrani et al. (2013) related the tourist's WTP to various characteristics and argue that psychological variables are better predicators of WTP than socio-economic variables. But one needs to consider the consumer's reactions to revenue and pricing tactics (Chapuis, 2012) resulting from different WTP among various market segments.

Price steering and personalization are also challenging the longstanding online travel agents (OTA) pricing agreements that underpin the online tourism industry's competitive landscape. For hoteliers, the OTA market the room for a percentage of the daily rate. In return, providers are required not to publish a rate beneath the daily rate (Demirçiftçi et al., 2010). Rate parity is expected to signal to firms' commitment to low price and reduce consumers' perceptions about the risk associated with buying online from a travel and tourism website. The rate parity enables OTAs the potential to provide price protection to consumers, to reduce their perceived price risk. Desmet, Nagard, and Vinzi (2012) examine how consumers react to price-matching guarantee and its perceptions and patronage intentions. While there has been some studies to explore steering from a macro or a personalization perspectives (Demirçiftçi et al., 2010; Hannak et al., 2014 ; ), and given the importance of rate parity in e-tourism, it is surprising that there is few evidence about the performance of price steering. The first research question is to identify if the performance of price steering is related to behavioral characteristics of market segments. 
Moreover, the knowledge of relationships with perceived fairness and trust at an individual level is important for managers to take relevant actions. There is a long history of marketing research over equity and fairness of transactions (Kahneman et al., 1986; Oliver \& Swan, 1989) as well as trust (Morgan \& Hunt, 1994). There is a lack of understanding of how price steering is influencing the consumer's perceptions during online shopping for tourism products from a theoretical, methodological and practical point of view. Two noteworthy exceptions, in the context of hotels, are the research of Mattila and Choi (2013) and of Smith et al. (2015). Smith et al. (2015) examine how cancelation policies, as an integral component of the purchase decision, determine willingness to pay. Their work highlights the role of the violation of distributive and procedural fairness on consumer patronage. Mattila and Choi (2013) investigate the rate fence of price discrimination by computer platform. Consumers are expected to adjust their behavior to price customization by changing their attitudes and their willingness to book with the OTA. Their results support the proposition that the consumers' reactions to tourism websites' discrimination are better understood and managed by considering ethical as well as gender issues but they are limited to only one scenario of price steering. The second research question of this paper explores the perceptions of consumers when they are confronting discriminations during the buying process.

The remaining of the paper is organized as follows. The first section attempts to answer these questions by reviewing the current literature on tourism marketing specifically addressing the price issue. Next, an empirical investigation reports the results of a study with an experimental design. The last section discusses the implications of the model and the findings.

\section{Conceptual framework}

\subsection{Price steering, hotel choice and willingness to pay}

Orbitz.com found that Apple users spend as much as 30\% more for a room night. The online travel site showed them different, and sometimes costlier, options than Windows visitors saw (Mattioli, 2012). Hannak et al. (2014) explore a way to measure price discrimination and price steering. E-commerce sites have been observed performing price steering: the practice of re-ordering search results to place expensive items towards the top of the page (Hannak et al. 2014). This "steering" practice, where users are presented different search results for products based on an inferred willingness to pay (Englehardt et $a l ., 2014$ ), is different than price discrimination. Since anybody just has to sort out the list to access to the same price -same product - same time.

The tactic is related to the assumption that Apple users are likely to pay more for a room. Apple users already stand out as big spenders. Nearly half of retailers in study by Forrester Research and Shop.org said users of tablets - a large majority of which are iPads - tend to place bigger online orders than users of laptops or desktops. Shoppers on Apple devices like iPhones also outspend shoppers using Android devices, accounting for half of all mobile purchases, according to International Business Machines, which tracks data from retailers. This point of view was the initial insight of Mattila \& Choi's (2013) study. 
Marketing analysts, reacting to the Orbitz story, state that if you're willing to shell out extra money for an iPad or MacBook, you may have more disposable income. They believe that Orbitz may be trying to skew their results for Mac users based on this assumption.

Willingness to pay is therefore a key concept between price discrimination and perceived fairness as suggested by Smith et al. (2015). They defined WTP as the measure of how likely a consumer is to engage in a purchase transaction and spend money. It allows an individual to take into account all the factors which are important to them in the purchase process of the valuation of the good or service. Sharifi-Tehrani et al. (2015) argue, in tourism, that motivation (needs) of consumers is responsible for their WTP. If Apple users have a higher WTP, then one expects they could select pricier hotels in a given list.

Therefore, this study aims testing whether the assumption is sound. As common sense tells us, anyone might have been using both apple and windows systems without the habit of paying different prices to purchase goods and services. In other words, would Apple users willing to spend more given the information set for everyone? To untie that issue, an experiment was run by swapping price information between Mac and Pc users in order to have a relevant reference to compare with. The first hypothesis postulates,

H1, that the steering of prices positively affects the willingness to pay of online buyers and pulls them to select certain products.

Moreover, even if the WTP is similar across market segments, product differentiation may still be appealing (in this case, steering information such that an online product search shows differently-priced results when online information systems personalize what is shown to a user). The willingness of online shoppers to pay higher prices for tourism products may originate from their attitudes or perceptions rather than merely from price steering. Accordingly, this study explores the perceptions of pricing fairness and trust toward OTA by consumers to tackle whether the performance of price steering is mediated through a network of causalities.

\subsection{Attitudes, perceived fairness and trust toward the OTA}

There is a long history of marketing research over equity and fairness of transactions (Kahneman et al., 1986; Oliver \& Swan, 1989). Adams (1965) defines a state of equity when one perceives that the ratio of one's contributions and rewards is equal to that of the other party. The breakdown of this proportionality results in the feeling of having been treated unfairly. Xia et al. (2004) define price fairness as a consumer's assessment and associated emotions of whether the difference (or lack of difference) between a seller's price and the price of a comparative other party is reasonable, acceptable, or justifiable. Within travel and tourism studies, the variety of pricing policies has resulted in conflicting evidence. Chapuis (2012) provided a synthesis of empirical findings about perceived fairness of price management.

The theory of distributive justice assumes that people are entitled to receive a reward that is proportional to what they have invested in a relationship (the equity norm). The theory 
of fairness assumes that a person compares his contributions and rewards of the transaction with another person as a reference (i.e., social comparison). Relevant to pricing, the procedural justice refers to the perceived fairness of policies, procedures, and criteria used by decision makers by which ends are accomplished (Heo \& Lee, 2010). People may seek to reduce the inequity within the relationship either by distorting contributions (e.g., trust) and/or rewards (e.g., satisfaction) in their own minds or by leaving the relationship.

The concept of trust is meaningful because it aims to preserve relational investments with partners (Morgan \& Hunt, 1994). Trust is a psychological state which reflects the confidence the consumer has in an exchange partner's ability, benevolence and integrity. Grewal et al. (2004) acknowledge that favorable attitudes are antecedents of high perceived fairness and trust. Consumers extend their fairness judgments to trust into transactional partners (MacMahon-Beatie et al. 2016,). Consumers with trust into, and intention to keep dealing with, a partner supposedly expect future benefits, such as discount and reduced price fluctuations to payoff short-term sacrifices. The experience of a price variation or of manipulation about price information affects the tourist's belief that the firm puts his/her concern first, so reduces its trust (Garbarino \& Maxwell, 2003). In the context of hotels, Smith et al. (2015) advance that the violation of fairness negatively affects the WTP derived of cancelation policies. Theoretically, the deduction from these arguments is that,

H2, the steering of prices negatively impacts perceived fairness and trust.

It also stands to reason the hypothesis,

H3, that the higher the perceived fairness and trust, the higher the willingness to pay.

To put in perspective the two research questions of this study, mobilizing the limited framework of Mattila \& Choi (2013) in one hand and Heo and Lee (2010) in the other hand, an interaction between efficiency and fairness is expected. Assuming H1, if the perceived fairness and trust do not intervene within the relationship between price steering and the consumer's choice then the practice should be generalized to many market segments. If the psychological stage is affecting this relationship then maintaining a perceived fairness and trust is key to benefit from price steering for some market segments. Subsequently, the hypothesis states,

H4 that the perceived fairness and trust is intervening in the effect of price steering on willingness to pay.

Attitudes, as a psychological tendency that is expressed with some degree of favor or disfavor, are important antecedents of perceptions and judgments. The perceived value of large inventories of rooms and of meta-search capabilities can generate positive attitudes toward OTA. The motivation of travelling tends to classify tourists-to-be as a segment of the market that has on average a fine attitude towards OTA. A positive attitude toward the goods provided by, and brands of, OTA is most likely to result in favorable perceptions, therefore higher WTP.

Overall, the model proposes an original answer to the research questions by posing the 
causality and the interactions between price steering, choice of a product in shopping online, perceived fairness, trust and willingness to pay. The figure 1 displays the resulting theory of consumer's reactions to price steering. The following section further investigates empirically the theoretical model.

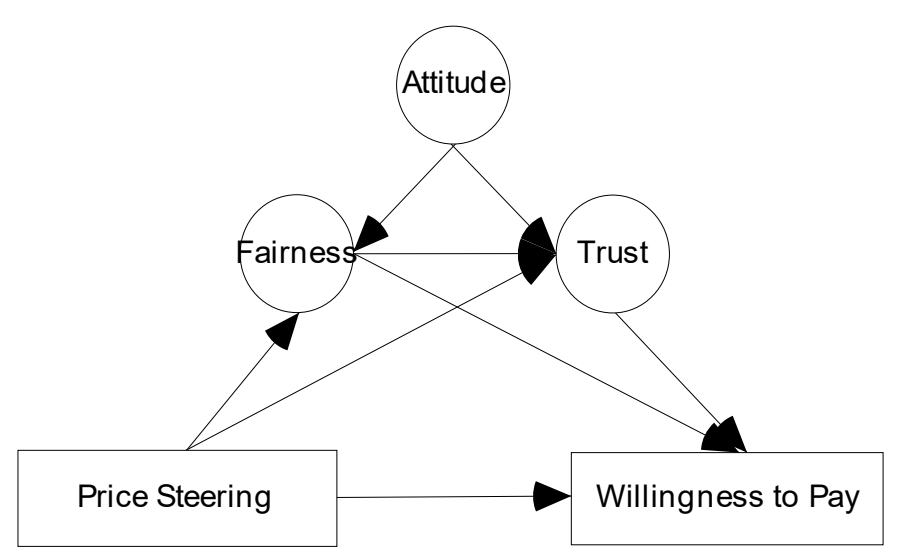

Figure 1. Proposed model of consumers' perceptions of price steering in shopping online for travel and tourism

\section{Empirical investigations}

\subsection{Methods}

A qualitative method with experimental treatment (Dwyer et al., 2012) is relevant according to the nature of the research questions and the data. The data analyzed to test the hypotheses were collected from a survey aimed at tourists-to-be, likely to book online.

\subsubsection{Procedures, sample and instrument development}

A survey simulating a hotel-booking request on travel agent website is developed in order to study online purchasers of a tourism product. The invitation was sent in January 2020 to professors of ten different hospitality/tourism universities and business schools in France, Spain, and Switzerland. Although conveniently chosen, they are representative of under, post graduates and doctorate students. It is plausible to consider the sample as representative of touristic behavior of Millennials booking online their travel and accommodation. Each professor invited their students to freely participate, distributed a survey link to her/his class and giving them the right to withdraw. As each respondent was informed of the topic, but unaware of the experiment, and was allowed to fill the questionnaire only once. The maturation and test biases are unlikely.

The data collection was running until at least 1,000 people were exposed to the treatments. $\mathrm{N}=883$ valid responses were collected from 1,005 students, within three months (Note 1). T-tests confirm no significant differences exist between early and late respondents' answers to the study variables in either sub-samples, reducing the likelihood of nonresponse bias. Regression to the mean is potentially a limitation as students majored in tourism, but the sample showed common psycho-sociological characteristics (Apple's market share with in Millenials). In order to restrict any potential contamination (from a 
respondent going quickly over the questionnaire, discovering the manipulation and telling to others), the data collection procedure ensures that each treatment group was physically separated. $77 \%$ of respondents were 20 to 24 years old, $22 \%$ were more than 25 (3\% were more than 40). 67\% are women. Respondents declared whether they are users of Apple branded products $(n=610$; being $69 \%$ of the sample) or not $(n=273)$, although it is unknown if they frequently use the two systems. No other pattern emerged suggesting differences in demographic or socio-psychological profiles.

The reliability of the instrument is maintained with clear procedures and checks. The experiment sets the prices and pictures as real as possible according to web requests for the period of survey. Three market managers from two worldwide OTAs double checked all materials before uploading the survey. The material included three sections. After a brief comment of the situation, respondents rated their attitudes toward OTA and provide psycho-sociological information. Having read the - randomly assigned - webpage of available hotels at destination, respondents were asked to select a hotel and declare how much they are likely to pay for each night. Next to that, an explanation of price steering is provided alongside a picture illustrating what others users have seen. Then respondents were asked to rate the fairness of the pricing and their trust of the OTA. The order of the items was randomized in the online survey for each respondent to avoid systematic response order effect. To reduce the potential for common method variance bias, the survey was consequently designed such that the independent and dependent variables were presented non-sequentially.

Inspired by Mattila and Choi (2013), two scenarios developed for this study were randomly assigned to respondents. The first one, scenario $\mathbf{A}$, is replicating the Wall Street Journal information (Mattioli, 2012) in which Apple users are steered to pricier hotels, with warmer colors, compared to PC users. 479 respondents (54\%) were exposed to that scenario A. Scenario B, with 404 respondents (46\%), was built by reversing the information between Apple users and PC users. In scenario B, PC users are steered to pricier hotels and Apple users seen the list of cheaper hotels. There is no significant difference across the subsamples related to age or operating system (OS) used.

\subsubsection{Measurement}

The attitude towards OTA is measured as a control for the analysis. The attitude toward $O T A$ was measured by two items using a Likert scale which is anchored by 'strongly disagree' $=1$ to 'strongly agree' $=5$. "It is very helpful to book accommodation from an OTA" was rated 3.70 on average (s.d. = .98) and "I think booking a room through OTA is good thing to do" got $\mathrm{m}=3.16($ s.d. $=1.17)$. The scale is somewhat reliable $(=.7)$.

The endogenous variables used to understand the consumer's decision-making are twofold. First, the pre-purchase stage is considered by two variables - chosen hotel, the choice of one hotel over seven alternatives and the willingness to pay. Second, the post-purchase stage is measured with the perceived fairness and the consumer's trust of OTAs. Three items evaluating perceived fairness with five-point scales are adapted from Oliver and Swan (1989) modifying them to fit the study settings. They are anchored at endpoint from 
'strongly disagree' $=1$ to 'strongly agree' $=5$. The scale of the perceived fairness scale is somewhat reliable ( $=.76)$. Drawn from Morgan and Hunt (1994) one's trust toward the OTA is measured with three five-point likert scales, related to the ability, integrity and intention items. The reliability is high $(=.81)$. Descriptive statistics of the items from the sample are given in Table 1.

The results indicate that many respondents agree on fair price after the presentation of the price steering, but pricing fairness get lower rank. Some (36\%) respondents disagree about the integrity of the reservation system. Many respondents declared their disagreement to continue using this OTA. In terms of controls, none of the variables are statistically $(p>.05)$ influenced by age, by OS system or gender.

Table 1. Descriptive statistics of items

Mean s.d. Skew. Kurt.

\begin{tabular}{|c|c|c|c|c|}
\hline Willingness to pay & 126.4 & 55 & 1.3 & 2.66 \\
\hline $\ln (\mathrm{WTP})$ & 4.75 & .43 & -.13 & .25 \\
\hline \multicolumn{5}{|l|}{ perceived fairness $(.76)$} \\
\hline I paid the reasonable price for my reservation & 3.28 & 1.03 & -.22 & -.32 \\
\hline The price that I was charged for my room was fair & 3.29 & 0.97 & -.27 & -.23 \\
\hline I was treated fairly by the orbitz's pricing process & 3.08 & 1.10 & -.18 & 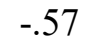 \\
\hline
\end{tabular}

Trust (.81)

$\begin{array}{llllll}\text { I believe Orbitz could be relied upon to keep its promise } & 3.13 & .97 & -.14 & -.32\end{array}$

Orbitz's reservation system has a high level of integrity $\quad \begin{array}{llll}2.80 & 1.05 & -.06 & -.56\end{array}$

$\begin{array}{lllll}\text { I want to continue dealing with Orbitz } & 2.83 & 1.10 & .08 & -.66\end{array}$

Note. 'strongly disagree' $=1$ to 'strongly agree' $=5$.

\subsection{Analysis and results}

The section conducts firstly the test of $\mathrm{H} 1$ that aims comparing chosen hotel and willingness to pay between respondents using different OS according to the same information (hotels sorted out in the same way) and same prices. Table 2 and Figure 2 provide evidence about how many times a given hotel is chosen when the information shows high prices, under both scenario A and B.

Over 488 respondents exposed to a list of pricier hotels, $58 \%$ of them choose a hotel within the first two sorted out on the top of the list. The other respondents choose mainly evenly in the rest of the list. The weighted average price of chosen hotel is about $\$ 150$ for 
both Apple and PC users. As nominal variable, the $X^{2}$ (chi-square) test is relevant to test whether its distribution is different between Apple and PC users. With $X^{2}(6)=8.29$ ( $p$ $=.22$ ), the Apple users do not select a hotel differently than PC users.

Table 2. Pricier hotels steered to respondents

\begin{tabular}{lllll}
\hline & & Scenario A & Scenario B & Total \\
& $\#$ & Apple users & PC users & \\
\hline Hyatt House & $\%$ & 125 & 57 & 182 \\
Design Suites & $\#$ & $36.0 \%$ & $40.4 \%$ & $37.3 \%$ \\
Catalina Hotel & $\%$ & 72 & 30 & 102 \\
& $\#$ & $20.7 \%$ & $21.3 \%$ & $20.9 \%$ \\
Churchill Suites & $\%$ & 17 & 12 & 29 \\
The Richmond Hotel & $\#$ & $4.9 \%$ & $8.5 \%$ & $5.9 \%$ \\
\multirow{2}{*}{ Eden Roc Renaissance } & $\#$ & 16 & 10 & 26 \\
& $\%$ & $4.6 \%$ & $7.1 \%$ & $5.3 \%$ \\
The Palms Hotel \& Spa & $\#$ & 38 & 12 & 50 \\
& $\%$ & $11.0 \%$ & $8.5 \%$ & $10.2 \%$ \\
\hline Total & $\%$ & 31 & 9 & 40 \\
Weighted average price of hotel chosen & $8.9 \%$ & $6.4 \%$ & $8.2 \%$ \\
\hline
\end{tabular}

Note. Hotel chosen given high prices list according to OS. \# means number of times a given hotel is chosen. \% means the proportion of choice.

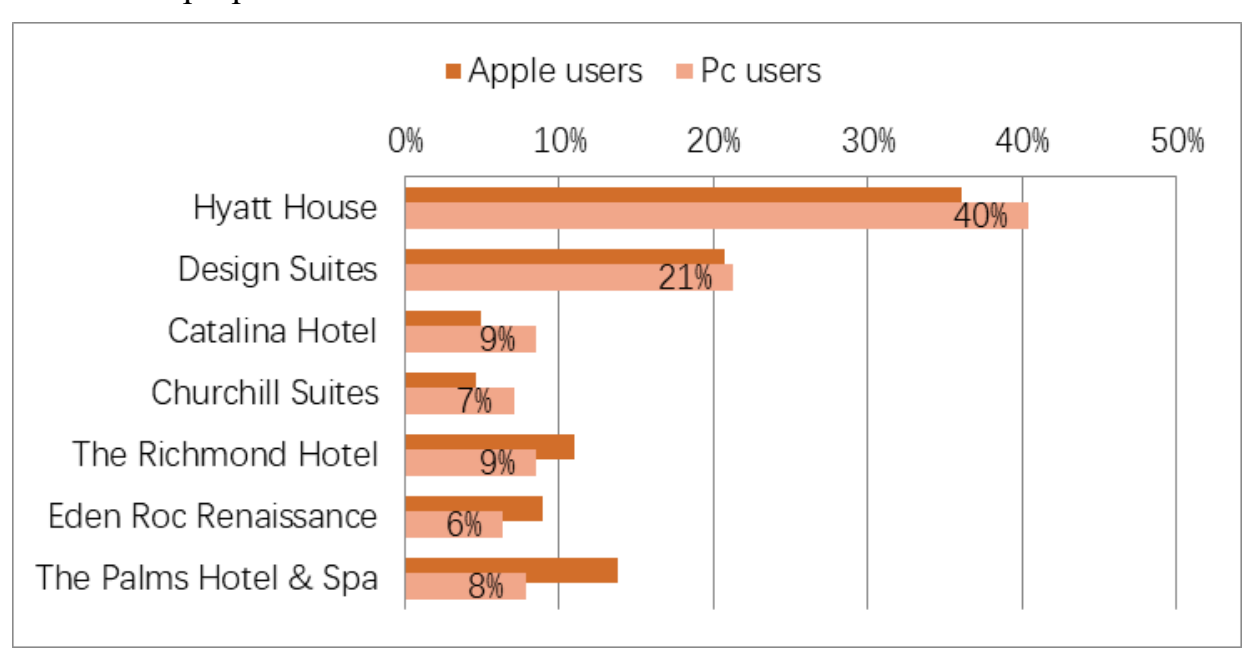

Figure 2. Proportion of choices given pricier hotels list according to OS

Table 3 and Figure 3 present the summary of findings from the data collected under scenario A and B, but low price list. As prior result, $56 \%$ of respondents select one of the 
first two out of alternatives shown. In contrast, some respondents got down of the list to select the cheaper hotel. The weighted average price of chosen hotel is about $\$ 125$ for both Apple and PC users. The null hypothesis that the distribution of the nominal variable is the same across treatment is not rejected $\left(X^{2}=6.91 ; p=.33\right)$.

Table 3. Cheaper hotels steered to respondents

\begin{tabular}{lllll}
\hline & & Scenario A & Scenario B & Total \\
& $\#$ & PC users & Apple users & \\
\hline Hyatt House & $\%$ & 52 & 91 & 143 \\
Design Suites & $\#$ & $39.4 \%$ & $34.6 \%$ & $36.2 \%$ \\
Catalina Hotel & $\%$ & 22 & 57 & 79 \\
& $\#$ & $16.7 \%$ & $21.7 \%$ & $20.0 \%$ \\
Churchill Suites & $\%$ & 7 & 7 & 14 \\
\multirow{3}{*}{ The Richmond Hotel } & $\#$ & $5.3 \%$ & $2.7 \%$ & $3.5 \%$ \\
& $\%$ & 4 & 6 & 10 \\
Ocean Spray & $\%$ & $3 . \%$ & $2.3 \%$ & $2.5 \%$ \\
& $\#$ & 8 & 28 & 36 \\
South Seas Hotel & $\%$ & $6.1 \%$ & $10.6 \%$ & $9.1 \%$ \\
& $\#$ & 33 & 56 & 89 \\
\hline \multirow{2}{*}{ Total } & $\%$ & $25 . \%$ & $21.3 \%$ & $22.5 \%$ \\
Weighted average price of hotel chosen & 6 & 18 & 24 \\
\hline
\end{tabular}

Note. Hotel chosen given low prices list according to OS. \# means number of times a given hotel is chosen. \% means the proportion of choice.

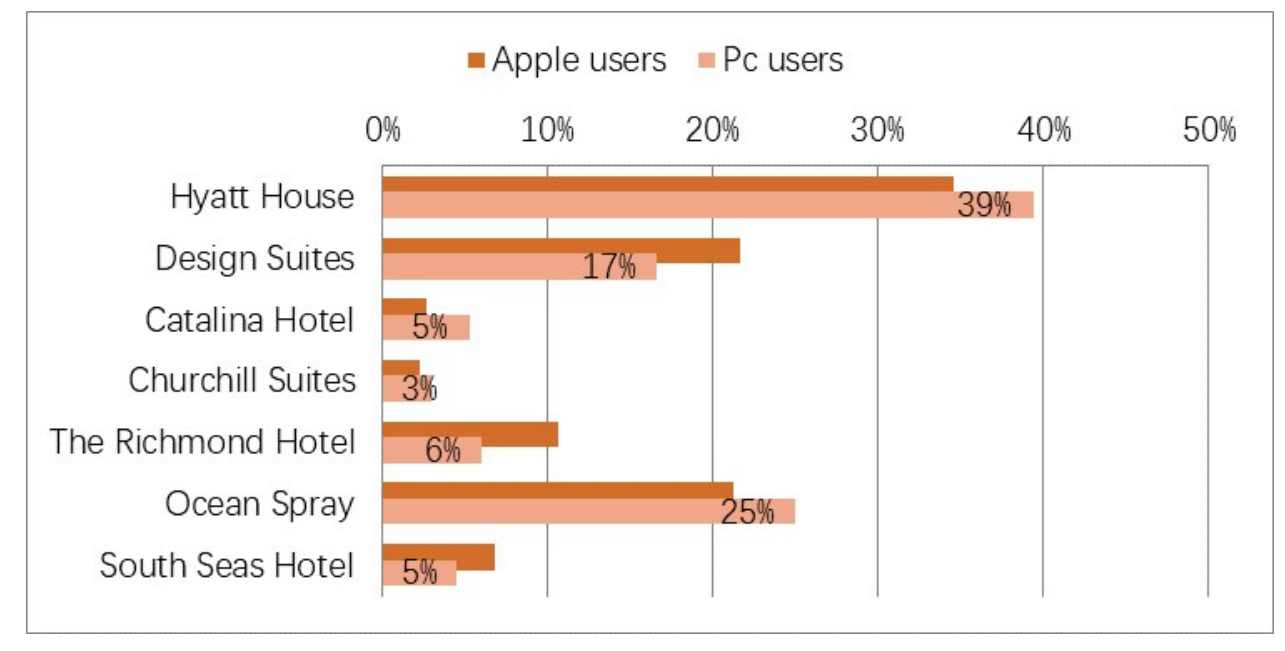

Figure 3. Proportion of choices given cheaper hotels list according to OS

The analysis turns to willingness to pay, a ratio variable, to increase its validity (see Table 
4 and Figure 4).

Table 4. How much are you likely to pay for a room?

\begin{tabular}{lllll} 
Scenario & OS & mean & s.d. & $\mathrm{n}$ \\
\hline A & PC User & $\$ 116.20$ & $\$ 44.38$ & 132 \\
& Apple user & $\$ 137.92$ & $\$ 60.90$ & 347 \\
\cline { 2 - 5 } & delta & $\$ 21.72$ & $\mathrm{t}=4.29$ & $\mathrm{p}<.00$ \\
& Total & $\$ 131.94$ & $\$ 57.61$ & 479 \\
\hline B & PC user & $\$ 137.05$ & $\$ 68.84$ & 141 \\
& Apple user & $\$ 110.63$ & $\$ 37.32$ & 263 \\
\cline { 2 - 5 } & delta & $\$-26.42$ & $\mathrm{t}=-4.23$ & $\mathrm{p}<.00$ \\
& Total & $\$ 119.85$ & $\$ 52.20$ & 404 \\
\hline Grand Total & & $\$ 126.41$ & $\$ 55.05$ & 883 \\
\hline
\end{tabular}

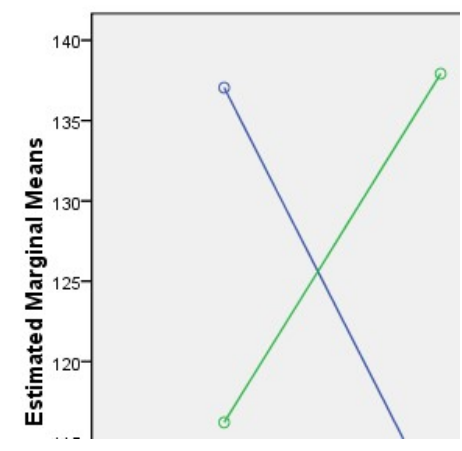

Notes. Green line is scenario A while blue line is scenario B. Abscise axe is whether the respondents are Apple users.

Figure 4. Estimated means of willingness to pay

Then an analysis of variance with interaction of OS and scenario is testing the hypothesis (H1) that price steering performance is not related to consumer/market segments but with willingness to pay. Table 5 documents that both main-factors (the scenario: $(F=.68$; $p>.05)$ and the OS: $(F=.02 ; p>.05))$ are not significantly influencing the willingness to $p a y$, in contrast to their interaction $(F=23.05 ; p<.00)$. 
Table 5. Analysis of variance of willingness to pay

\begin{tabular}{lllc}
\hline Source & Degree of fredoom & Mean Square & F value \\
\hline Scenario & 1 & 0.12 & 0.68 \\
OS & 1 & 0.00 & 0.02 \\
Scenario * OS & 1 & 4.08 & $23.05^{* * *}$ \\
Error & 879 & 0.18 & \\
Total & 883 & & \\
\hline
\end{tabular}

Consistent with results of prior studies (only scenario A), Apple users (\$138) are found to significantly be willing to spend about $\$ 21$ more than PC users $(\$ 116)(t=4.29 ; p<.00)$. However, the results are the opposite once the scenarios are reversed. Apple users $(\$ 110)$ are significantly willing to spend about $\$ 26$ less than PC users $(\$ 137)(t=-4.23 ; p<.00)$. The mean of willingness to pay while pricier hotels are steered to any users $(\$ 137.67, \mathrm{n}=$ $488)$ is significantly higher than cheaper hotels steered to any users $(\$ 112.49, \mathrm{n}=395 ; t=$ $7.20 ; p<.00)$. Thus, only price levels shown in a given order sorted out has an effect. Therefore, this observation shows that the assumption of the performance of price steering related to characteristics of individuals in a market segment turns wrong.

Therefore the analysis of the first-step endogenous shows convergence, increasing the validity of the measurement. The results of willingness to pay mirror the findings for hotel chosen. Thus, Hypothesis $\mathbf{1}$ is supported.

This section also conducts the test of H2-4 in which the consumer's perceptions are expected to affect its willingness to pay. These supposed relationships between the endogenous constructs, perceived fairness and trust toward the OTA, are capturing the post-purchase stage. In accordance, a structural equation modeling is statistically assessing causal relationships simultaneously involving measures assumed to reflect unobservable variables, such as fairness. A price steering variable is coded as a dummy variable which takes the value of 1 when respondents were exposed to the list of pricier hotels $(n=488)$, 0 otherwise $(\mathrm{n}=395)$. The willingness to pay has a logarithmic transformation. The findings of the initial confirmatory factorial analysis indicated that the constructs perceived fairness and trust of OTAs exerted a significant influence on the item pricing fairness. The unidimensional measurement for each set of items as formalized by a multiple-indicator measurement model (Gerbing \& Anderson, 1988) could not be achieved successfully until the item is deleted from the model. Table 6 presents the standardized estimates of the factor loadings and other statistics. 
Table 6. Measurement model

2021, Vol. 13, No. 3

\begin{tabular}{|c|c|c|c|c|}
\hline Construct (AVE) & Item & & $t$-value & $\mathrm{R}^{2}$ \\
\hline perceived fairness & I paid the reasonable price for my res... & 0.88 & $22.01^{* * *}$ & 0.77 \\
\hline$(0.63)$ & The price that I was charged for my... & 0.71 & $18.54^{* * *}$ & 0.50 \\
\hline \multirow[t]{3}{*}{ trust $(0.61)$} & I want to continue dealing with OTA OTA's & 0.87 & $28.94^{* * *}$ & 0.75 \\
\hline & reservation system has a high ... & 0.81 & $26.54^{* * *}$ & 0.66 \\
\hline & I believe OTA could be relied upon to ... & 0.66 & $20.40^{* * *}$ & 0.44 \\
\hline \multirow[t]{2}{*}{ attitude $(0.55)$} & It is very helpful to book accommodation & 0.80 & $13.33^{* * *}$ & 0.64 \\
\hline & I think booking a room through OTA is . & 0.67 & $12.52^{* * *}$ & 0.45 \\
\hline
\end{tabular}

$\chi_{(11)}^{2}=61.65 ; \chi^{2}{ }_{\text {d.f. }}=5.60 ; p<.00 ;$ AGFI $=0.95 ;$ RMSEA $=0.07$

Note. are the standardized factor loadings. ${ }^{* * *}$ indicates $p$-values lower than $0.01, \mathrm{AVE}=$ average variance extracted, AGFI $=$ adjusted goodness-of-fit index, RMSEA $=$ root mean square error of approximation.

The goodness-of-fit statistics related to the model are large. As evidence of convergent validity, all items load only on their respective factor and all measurement factor loadings are significant thought the lowest is $=.66$. The discriminant validity presumes that a construct should share more variance with its measures than it shares with other constructs (Fornell \& Lacker, 1981). As the highest correlation is $=.55(p<.01)$ between perceived fairness and trust toward the OTA, the empirical multidimensionality of the model is acceptable. Overall the factorial structure of the data is supported by the analysis. Table 7 illustrates the estimates of the path coefficients, acceptable for testing the hypotheses $\left(\chi_{(11)}^{2}=61.65 ; \chi^{2} /\right.$ d.f. $\left.=5.60 ; p<.00\right)$.

Table 7. Path estimates of the proposed model

\begin{tabular}{|c|c|c|c|}
\hline Hypothesis & Coefficient & $\begin{array}{l}\text { Standardized } \\
\text { Estimate }\end{array}$ & $t$-value \\
\hline & & -0.10 & $-2.61^{* * *}$ \\
\hline & & 0.01 & 0.15 \\
\hline & & 0.20 & $5.98^{* * *}$ \\
\hline & & 0.21 & $4.49^{* * *}$ \\
\hline & & 0.24 & $5.77^{* * *}$ \\
\hline & & 0.50 & $10.87^{* * *}$ \\
\hline & & 0.16 & $3.33^{* * *}$ \\
\hline & & -0.02 & -0.50 \\
\hline
\end{tabular}

Note. ${ }^{* * *}$ indicates $p$-values lower than 0.01 .

The global goodness-of-fit statistics indicate the structural model represents the data structure well. Turning to the path analysis, a list of pricier hotels triggers a perception unfairness $(=-.10)$ but increases the willingness to pay $(=.20)$, supporting H1 while controlling for the effect of other variables. However, the trust of respondents 
toward the OTA is not influenced directly $(=.01)$ but only indirectly. Next, the literature is supported since a positive attitude raises perceived fairness $(=.21)$ and trust $(=.24)$. Moreover, a fair transaction increases the trust in the provider ( $=.50)$. The hypothesis that price steering impacts negatively perceived fairness and trust, H2 is supported. The main topic of this study is how price steering and perceived fairness/trust intervenes. The hypothesis that of a direct effect, $\mathbf{H 3}$, is partially accepted as only perceived fairness increases willingness to pay $(=.16)$. As trust does not influence willingness to pay ( $=-.02$ ), the relationship between the price steering and willingness to pay is not fully mediated, partially rejecting $\mathrm{H} 4$. To test the effects predicted in $\mathrm{H} 4$, the test consists in constraining the coefficient $(=0)$ in order to compare the total effect of price steering to its direct effect on willingness to pay. The mediation of perceived fairness is statistically significant $\left(X_{(1)}^{2}=6.9 ; p<.01\right)$ but economically marginal. Thus, Hypothesis 4 is partially rejected. Last, the results are deeply discussed in the next section.

\section{Discussions and recommendations}

Research into the relationship between price steering, consumers' perceptions and willingness to pay is important from theoretical as well as managerial perspectives as it may help answer the question of discrimination in pricing schemes. Based on an original experimental design, the main contribution of this paper is evaluating the performance of price steering as well as the interference of perceptions. As an implication in the field of tourism, managers and researchers alike should carefully tailor the pricing schemes to maintain fairness, as well as profitability, by considering rate parity across online channels and purchasing experiences. Following the empirical analysis, the discussion of results is threefold for managers.

Arguably from this study, the sorting of information on prices is causing purchasers to behave differently. The current findings are consistent with the framing effect highlighted by marketing and psychology theories. This study documents the main effect of price steering such as a higher willingness to pay and driving online purchasers toward certain choices. Therefore, arguing that the purchasing power of Apple users as a proxy for a demand of top-end products is fallacious. The $20-30 \%$ difference, found in prior surveys is related to a discrimination of information. These findings are consistent with Mattila and Choi (2013) who provided the empirical evidence of scenario A of hypothesis H1. They found that consumers question the ethics of the presentation of rates based on the platform used to search for hotels on the internet. They suggested that information about differential pricing policy lowered the consumers' willingness to book regardless of their gender. Unlike Mattila and Choi's (2013) results, no difference is found between men and women in this current study. Moreover, the test procedure shows that the two measures of the endogenous variables are convergent, increasing reliability of the survey. Instead, the impact on willingness to pay is related to how the list of hotels is sorted. These results are of particular importance due to their impact on OTAs' policies.

The study evaluates how the performance of price steering is affected in the post-purchase stage by the perceptions of fairness and trust, finding evidence that the influence exists. 
These e-commerce practices create uncertainty and lack of trust in online providers. The findings are consistent with the study of Smith et al. (2015) who confirmed that violations of fairness eliminate the positive effect of more liberal cancelation policies on WTP. The hypothesis that price steering causes a decrease of consumer's trust in the provider is partially supported by the data, adding new evidence for Chapuis (2012) H2 and H3. His model explain how unfavorable experiences of revenue management result in a lower consumer trust toward the firm. The consumer is likely to keep seeking information when $\mathrm{s} / \mathrm{he}$ perceived a price or information discrepancy.

The study is a novel contribution to the management research literature because, as far as we know, it is the first research to jointly address the price steering practices in a relational marketing approach within the field of the tourism industry. Beside the previous two points, several extensions of academic literature also provide practical implications. For a provider, it's better to be sorted out on the top of the page to sell some products. Moreover, hoteliers should care about services provided by OTA, up to the color of their posts. The OTAs can enforce the rate parity contract provisions in exchange for providing hoteliers with a substantial amount of occupancy as result of their greater scale and marketing efficiency (Demirçiftçi et al., 2010). An OTA has a strong market power to pull rate parity from hoteliers (written in contract or not) by steering prices according to the commission or the respect of rate parity. The findings of this study suggest the hoteliers to maintain price parity across public channels in order to prevent the opportunism of OTA to steer hotel rooms.

The caveats of the limitations of this research are warranted. Revealed preference data has the advantage of assessing actual decisions made, whereas this study relies on stated preference in a hypothetical decision. While the latter offers the possibility to manipulate characteristics in order to estimate the influence of fairness and trust, the former should be more practical for OTAs and tourism providers alike in designing price steering. Another limitation arguing that hypothetically measured WTP may be higher than the real WTP (Sharifi-Tehrani et al., 2013) is overcome as the comparative nature of analysis limits this bias between the groups of respondents. This study overall discourages the implementation of price steering, whereby a reasonable increase in the revenues be achievable by a discrimination, in order to increase both the economic and the fairness perception of transactions.

\section{Notes}

Note 1. Actually, the data was fully collected few days before the Covid outbreak in Europe.

\section{References}

Adams, J. S. (1965). Inequity in social exchange. Advances in experimental social psychology, 2, 267-299. https://doi.org/10.1016/S0065-2601(08)60108-2

Bolton, L.E., Warlop, L., \& Alba, J. (2003). Consumer perceptions of price (un)fairness. Journal of Consumer Research, 29(4), 474-492. https://doi.org/10.1086/346244

Chapuis, J. M. (2012). Perceived fairness and trust in consumer's reactions to revenue 
management. International Journal of Revenue Management, 6(3-4), 145-157. https://doi.org/10.1504/IJRM.2012.050381

Chiames, C. (2014). OWW to Christo Wilson. http://personalization.ccs.neu.edu/Projects/ PriceDiscrimination/Responses/Orbitz/OWW\%20to\%20Christo\%20Wilson.pdf

Demirçiftçi, T., Cobanoglu, C., Beldona, S., \& Cummings, P. R. (2010). Room rate parity analysis across different hotel distribution channels in the US. Journal of Hospitality Marketing \& Management, 19(4), 295-308. https://doi.org/10.1080/19368621003667010

Desmet, P., Le Nagard, E., \& Vinzi, V. E. (2012). Refund depth effects on the impact of price-beating guarantees. Journal of Business Research, 65(5), 603-608. https://doi.org/10.1016/j.jbusres.2011.02.034

Dwyer, L., Gill, A. \& Seetaram, N. (2012) Handbook of Research Methods in Tourism. Quantitative and Qualitative Approaches. EE - Chapter 6 https://doi.org/10.4337/9781781001295

Englehardt, S., Eubank, C., Zimmerman, P., Reisman, D., \& Narayanan, A. (2014). Web privacy measurement: Scientific principles, engineering platform, and new results. Manuscript posted at http://randomwalker.info/publications/WebPrivacyMeasurement.pdf

Fornell, C., \& Larcker, D. F. (1981). Structural equation models with unobservable variables and measurement error: Algebra and statistics. Journal of Marketing Research, 382-388. https://doi.org/10.1177/002224378101800313

Garbarino, E. \& Maxwell, S. (2010). Consumer response to norm-breaking pricing events in e-commerce. Journal of Business Research, 63(9), 1066-1072. https://doi.org/10.1016/j.jbusres.2008.12.010

Gerbing, D. W., \& Anderson, J. C. (1988). An updated paradigm for scale development incorporating unidimensionality and its assessment. Journal of Marketing Research, 186-192. https://doi.org/10.1177/002224378802500207

Hannak, A., Soeller, G., Lazer, D., Mislove, A., \& Wilson, C. (2014). Measuring price discrimination and steering on e-commerce web sites. In Proceedings of the 2014 Conference on Internet Measurement Conference (pp. 305-318). ACM. https://doi.org/10.1145/2663716.2663744

Heo, C. Y., \& Lee, S. (2010). Customers' perceptions of demand-driven pricing in revenue management context: comparisons of six tourism and hospitality industries. International Journal of Revenue Management, 4(3-4), 382-402. https://doi.org/10.1504/IJRM.2010.036030

Kahneman, D., Knetsch, J. L., \& Thaler, R. (1986). Fairness as a constraint on profit seeking: Entitlements in the market. The American Economic Review, 728-741.

Kahneman, D., \& Tversky, A. (2013). Prospect theory: An analysis of decision under risk. In Handbook of the fundamentals of financial decision making, part I, 99-127. https://doi.org/10.1142/9789814417358_0006 
Kimes, S. E., \& Wirtz, J. (2003). Has revenue management become acceptable? Findings from an international study on the perceived fairness of rate fences. Journal of Service Research, 6(2), 125-135. https://doi.org/10.1177/1094670503257038

McMahon-Beattie, U., McEntee, M., McKenna, R., Yeoman, I., \& Hollywood, L. (2016). Revenue management, pricing and the consumer. Journal of Revenue and Pricing Management, 15(3-4), 299-305. https://doi.org/10.1057/rpm.2016.17

Mattila, A. S., \& Choi, C. (2013). An Analysis of consumers' reactions to travel websites' discrimination by computer platform. Cornell Hospitality Quarterly, 55(2), 210-215.

Mattioli, D. (2012). On Orbitz, Mac users steered to pricier hotels. The Wall Street Journal, http://online.wsj.com/article/SB10001424052702304458604577488822667325882.html

Morgan, R.M. \& Hunt, S.D. (1994). The commitment-trust theory of relationship marketing. Journal of Marketing, 20-38. https://doi.org/10.1177/1938965513509879

Oliver, R.L. \& Swan, J.E. (1989). Consumer perceptions of interpersonal equity and satisfaction in transactions: a field survey approach. Journal of Marketing, 53(2), 21-35. https://doi.org/10.1177/002224298905300202

Reynisdottir, M., Song, H., \& Agrusa, J. (2008). Willingness to pay entrance fees to natural attractions: An Icelandic case study. Tourism Management, 29(6), 1076-1083. https://doi.org/10.1016/j.tourman.2008.02.016

Rothman, A. J., \& Salovey, P. (1997). Shaping perceptions to motivate healthy behavior: the role of message framing. Psychological bulletin, 121(1), 3. https://doi.org/10.1037/0033-2909.121.1.3

Sharifi-Tehrani, M., Verbič, M., \& Chung, J. Y. (2013). An analysis of adopting dual pricing for museums: The case of the national museum of Iran. Annals of Tourism Research, 43, 58-80. https://doi.org/10.1016/j.annals.2013.04.001

Xia, L., Monroe, K. B., \& Cox, J. L. (2004). The price is unfair! A conceptual framework of price fairness perceptions. Journal of Marketing, 68(4), 1-15. https://doi.org/10.1509/jmkg.68.4.1.42733 